\title{
Beneficial effects of fish stocking on performance and pest control in the lotus field system
}

\author{
Li Ma ${ }^{1}$, Jie Zhu ${ }^{1}$, Qi Chen ${ }^{1}$, Wei $\mathrm{Li}^{2, *}$, Guo-Hua Huang ${ }^{1, *}$ \\ ${ }^{1}$ Hunan Provincial Key Laboratory for Biology and Control of Plant Diseases and Insect Pests, Hunan Agricultural University, \\ Changsha 410128, Hunan, PR China \\ ${ }^{2}$ State Key Laboratory of Freshwater Ecology and Biotechnology, Institute of Hydrobiology, Chinese Academy of Sciences, \\ Wuhan 430072, Hubei, PR China
}

\begin{abstract}
The present study was conducted to evaluate the economic effects of fish stocking on plant and fish performance in lotus fields, as well as to determine its influence on controlling common pest species associated with lotus fields. Lotus yield, fish growth performance, economic returns and pest abundance at 5 fish stocking density treatments $(0,1500,3000,4500$ and 6000 ind. $\mathrm{ha}^{-1}$ ) were determined in 15 separate lotus fields at a lotus farming facility in Wugang City, Hunan Province, China. The results showed a tendency for the lotus yield to increase with fish stocking density, but significant differences were not found among the treatments. Survival rates were not significantly different among the fish stocking treatments for the 3 species of carp tested. Absolute growth rate and specific growth rate showed similar trends, with their values significantly decreasing as stocking density increased for each carp species. The total yield for the 3 fish species did show significant differences, with the highest yield in the 6000 treatment and the lowest in the 1500 treatment. Total net income was highest in the 4500 treatment and lowest in the control (0) treatment. No significant differences were observed between the 4500 and 3000 treatments. The abundance levels of 3 types of pests were lower in the fish stocking treatments than in the control treatment, and were shown to decrease with increasing stocking density. Based on these observations, stocking densities of 3000 to 4200 total ind. ha ${ }^{-1}$ were considered optimal levels in lotus-fish culture systems.
\end{abstract}

KEY WORDS: Growth efficiency $\cdot$ Lotus-fish culture $\cdot$ Nelumbo nucifera $\cdot$ Carps $\cdot$ Stocking density $\cdot$ Performance $\cdot$ Economic benefit $\cdot$ Pest control

\section{INTRODUCTION}

Nelumbo nucifera Gaertn., also known as Indian lotus or sacred lotus, is an aquatic herbaceous perennial plant that has an extremely long history in cultivation as a popular and economically important cash crop in many Asian countries (Yi et al. 2002). All parts of the lotus plant are highly valued, whether for their use as a vegetable food source, as ornamental plants or for medicinal applications. For example, lotus rhizomes are considered a major vegetable crop in Asia (Tian et al. 2009). Lotus has also become a potentially important crop in Australia (Nguyen 2001), New

${ }^{*}$ Corresponding authors: liwei@ihb.ac.cn; ghhuang@hunau.edu.cn
Zealand (Follett \& Douglas 2003) and the United States (Tian et al. 2006). In China, lotus has a wide distribution, extending from southern Hainan Province to northern Heilongjiang Province, and from eastern Taiwan to the western Tian Mountains in Xinjiang Province. The cultivated area of lotus planted for vegetables in China currently exceeds $5000 \mathrm{~km}^{2}$, which is now the largest crop area devoted to growing aquatic vegetable in the country (Ke et al. 2015).

Historically, lotus has been planted in ponds for vegetable production. Recently, however, planting in paddy fields has become increasingly popular. Previ-

() The authors 2017. Open Access under Creative Commons by Attribution Licence. Use, distribution and reproduction are unrestricted. Authors and original publication must be credited. 
ous studies have shown that planting lotus in paddy fields could be more profitable than planting rice (e.g. Liu \& Fu 2004). However, the widespread proliferation of pests and weeds in lotus fields has often led to a serious decline in output and quality in the harvest of lotus (Xiong et al. 2010). Traditional chemical control has been an effective means for pest and weed suppression in lotus fields, but it obviously presents a number of challenges; for example, the pesticides used may lead to water pollution (Tan et al. 2003). Biological control methods, however, may eliminate many of the drawbacks of chemical control. The introduction of fish culture has often been suggested as a feasible method for pest and weed control in lotus fields.

In China, the co-culture or rotated culture of lotus and fish in ponds has been practiced for many years (Yi et al. 2002). The practice of co-culturing lotus and fish in paddies could yield a higher net return than planting lotus alone (Yi et al. 2002). It also is effective in removing nitrogen and phosphorus contaminants from old pond sediment, while the lotus improves the aquacultural environment compared to the model of culturing fish alone (Chen \& Li 2007). The model of rotating fish and aquatic vegetables would allow producers to bring 2 crops to market rather than 1, and would act as a buffer if a loss occurred in one of the two ventures (Edwards 1987). However, little is currently known about stocking parameters of fish in lotus fields and the effects they have on pest populations, although a limited number of papers are available on the production and economic benefits of lotus-fish co-culture techniques (Wu 2005). Because so little research has been conducted on identifying the optimal stocking parameters, including fish species to be stocked and stocking density, it is essential to determine the optimal parameters to maximize the performance of the fish species selected and their success in controlling pests in lotus fields.

Accordingly, we hypothesized that fish co-cultured in the lotus field systems at an appropriate stocking density could aid in pest control and result in increased economic benefits. In this study, 3 carp species with different trophic or spatial niches were selected and stocked in lotus fields at 5 stocking densities. We compared the production of lotus, the growth, survival and production of the stocked fish, the integrated economic benefit, and the abundance of pests with the 5 treatments. The aim of this study was to evaluate the economic effects of fish stocking on plant and fish performance in lotus fields, as well as to determine the influence of fish stocking on controlling common pest species associated with lotus fields, and to identify the optimal co-culture fish species and density in the fields. Results from this study will enable efficient management and maximize profitability of the co-culture model of lotus and fish in lotus fields.

\section{MATERIALS AND METHODS}

\section{Lotus field facilities and experimental design}

This study was conducted using a randomized complete block design in 15 fields with surface areas ranging from 0.100 to 0.187 ha in Wugang City, Hunan Province, southern China, from March to November 2014 (Fig. 1). Five fish stocking density treatments - 1 control (no fish) and 4 treatments $\left(1500,3000,4500\right.$ and 6000 ind. ha $\left.{ }^{-1}\right)$, each in triplicate-were used in the study (Table 1). Prior to the experiment, the ridge of each field was heightened and consolidated. For those fields stocked with fish, peripheral trenches $(1 \times 0.6 \mathrm{~m}$, width $\times$ depth $)$, linked with a cross-shaped trench in the field $(0.8 \times 0.5 \mathrm{~m}$, width $\times$ depth) with an area of $10 \%$ of the field area, were dug to serve as fish refuges. In the field, screened inlets and outlets ( $2 \mathrm{~mm}$ mesh size) were installed to prevent indigenous fish and aquatic predators from entering the fields and to prevent stocked fish from escaping.

At the beginning of the experiment, the fields were harrowed, puddled and then leveled. Seedlings of the 'Elian 7' lotus variety, purchased from the Wuhan Vegetable Research Institute, were transplanted to fields of the 5 treatments at a constant density of $4500 \mathrm{~kg} \mathrm{ha}^{-1}$ on 4 April 2014. The average length and weight of the transplanted lotus seedlings were $0.95 \mathrm{~m}$ and $2.50 \mathrm{~kg}$, respectively. After the lotus seedlings were transplanted, water was added weekly to all fields and the water depth was increased as the height of lotus increased. Identical amounts of fertilizer were used as a basal dressing $1 \mathrm{~d}$ prior to transplanting and as top-dressing $50 \mathrm{~d}$ after transplanting. No herbicides or pesticides were applied to any of the treatments during the experiments.

Healthy fingerlings of triploid Xiangyun crucian carp Carassius auratus (L.) (initial mean weight: $93.5 \pm$ $8.8 \mathrm{~g}$, mean $\pm \mathrm{SD}$ ), triploid Xiangyun common carp Cyprinus carpio L. $(117.2 \pm 11.7 \mathrm{~g})$ and grass carp Ctenopharyngodon idellus (Valenciennes) (413.7 \pm $16.9 \mathrm{~g}$ ), obtained from a nearby carp hatchery, were stocked at densities for the 3 species combined of 0 , 1500, 3000, 4500 and 6000 ind. ha ${ }^{-1}$ on 22 May 2014 (Table 1). No supplemental food was provided to the 


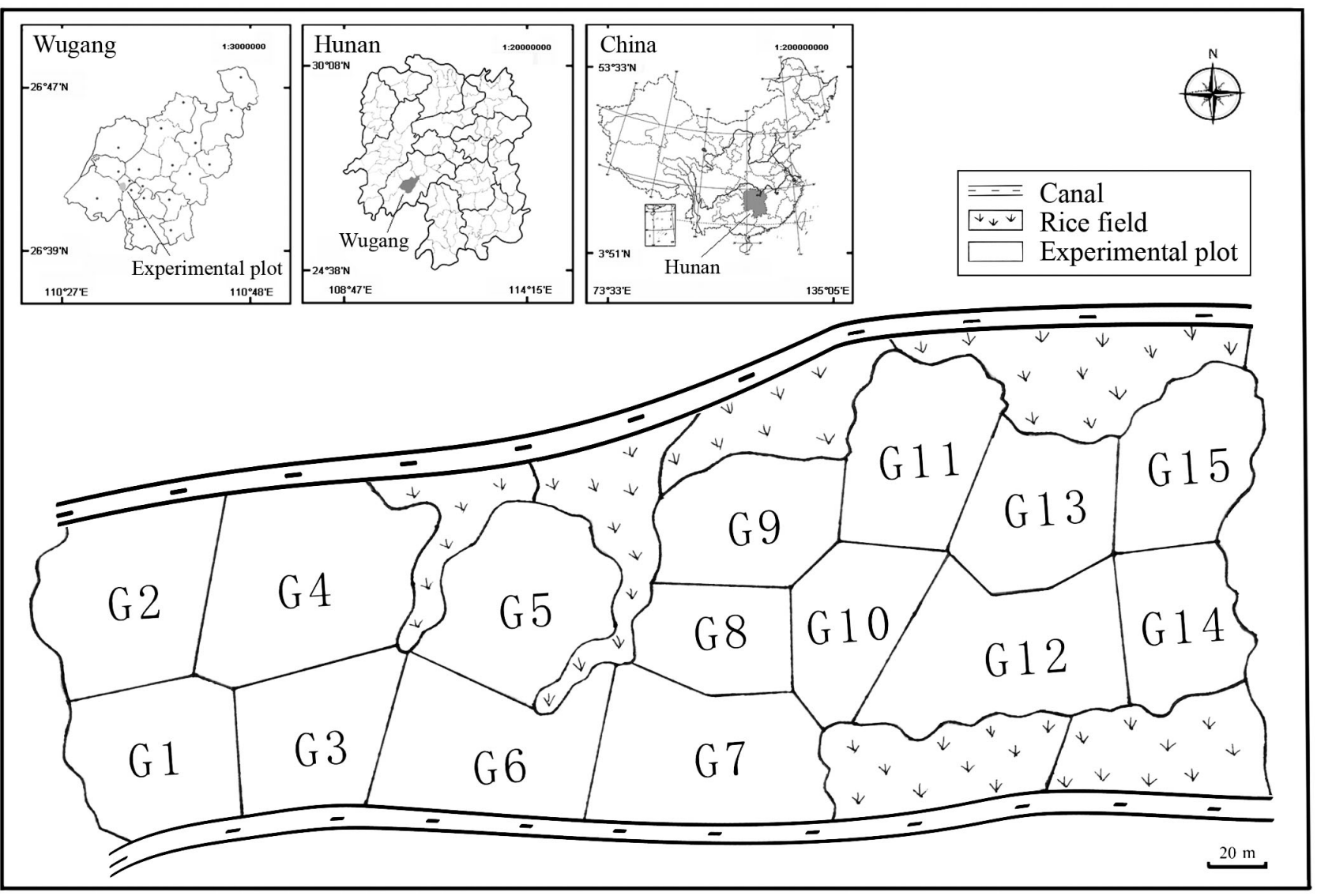

Fig. 1. Map of the experimental site in Wugang City, Hunan Province, southern China (insets), showing the distribution and area size of each lotus field (G1-G15)

fish during the experiment. The fish were reared for $210 \mathrm{~d}$ and then harvested after draining the fields.

The investigation of pests was conducted using the 5-point sampling method on each field once per week
(Ma et al. 2016). The fields were sampled regularly from 23 May (when fish were stocked) to 19 September 2014 (when lotus plants withered). The diameter of the sampling point in the field was $1 \mathrm{~m}$, where all

Table 1. Fish stocking scheme in lotus fields

\begin{tabular}{|c|c|c|c|c|c|c|c|c|}
\hline \multirow[t]{2}{*}{ Treatment } & \multicolumn{3}{|c|}{$\longrightarrow$ Stocking density (ind. ha ${ }^{-1}$ ) } & \multirow{2}{*}{$\begin{array}{c}\text { Field } \\
\text { number }\end{array}$} & \multirow{2}{*}{$\begin{array}{c}\text { Field } \\
\text { size (ha) }\end{array}$} & \multicolumn{3}{|c|}{$\longrightarrow$ Stocking amount (individuals) } \\
\hline & Crucian carp & Common carp & Grass carp & & & Crucian carp & Common carp & Grass carp \\
\hline \multirow[t]{3}{*}{ I } & 0 & 0 & 0 & G2 & 0.100 & 0 & 0 & 0 \\
\hline & & & & G5 & 0.080 & 0 & 0 & 0 \\
\hline & & & & G8 & 0.073 & 0 & 0 & 0 \\
\hline \multirow[t]{3}{*}{ II } & 600 & 600 & 300 & G7 & 0.173 & 104 & 104 & 52 \\
\hline & & & & G9 & 0.120 & 72 & 72 & 36 \\
\hline & & & & G11 & 0.107 & 64 & 64 & 32 \\
\hline \multirow[t]{3}{*}{ III } & 1200 & 1200 & 600 & G6 & 0.187 & 224 & 224 & 112 \\
\hline & & & & G10 & 0.073 & 88 & 88 & 44 \\
\hline & & & & G13 & 0.120 & 144 & 144 & 72 \\
\hline \multirow[t]{3}{*}{ IV } & 1800 & 1800 & 900 & G12 & 0.167 & 300 & 300 & 150 \\
\hline & & & & G14 & 0.107 & 192 & 192 & 96 \\
\hline & & & & G15 & 0.107 & 192 & 192 & 96 \\
\hline \multirow[t]{3}{*}{ V } & 2400 & 2400 & 1200 & G1 & 0.080 & 192 & 192 & 96 \\
\hline & & & & G3 & 0.100 & 240 & 240 & 120 \\
\hline & & & & G4 & 0.187 & 448 & 448 & 224 \\
\hline
\end{tabular}


lotus plants within the 1-m circle were thoroughly surveyed for pest individuals. All pest individuals in the sampling sites were recorded using the following investigation method. The plants were checked from left to right, from top to bottom and from the upper surface of the blades to the lower surface of the blades. When a species was difficult to identify in the field, a photo was taken and the specimens were collected. Every photo and/or specimen was given a unique record number and identified in the laboratory. Weather conditions were recorded during the entire sampling period. The collected pest specimens were identified using the Huang \& Li (2013) identification guide.

At the end of the experimental period, the number and individual weight of fish was recorded. Growth performance of the fish was evaluated using survival, relative weight gain (WG), specific growth rate (SGR), absolute growth rate (AGR) and total yield (Hossain et al. 2013). Before determining the total lotus harvest yield of each field, the lotus roots were placed in ditches and then the adhering mud was removed from each lotus plant. Temperature, dissolved oxygen and $\mathrm{pH}$ were recorded daily in each field between 07:00 and 08:00 h using portable electronic probes. All measurements were found to be in the acceptable range for carp culture. The water levels were measured daily using a graduated stick placed in each lotus field.

\section{Economic benefit analysis}

The economic analysis followed that of Gomes et al. (2006). Total net income equaled total revenue minus total cost. The total revenue included that of harvested lotus and fish, sold at 6 yuan $\mathrm{kg}^{-1}$ for lotus, 12 yuan $\mathrm{kg}^{-1}$ for crucian carp and common carp, and 14 yuan $\mathrm{kg}^{-1}$ for grass carp on the local market. The total costs consisted of the cost of the lotus seedlings (8 yuan $\mathrm{kg}^{-1}$ ), fish fingerlings $(1.2,1.3$ and 8 yuan ind. ${ }^{-1}$ for crucian carp, common carp and grass carp, respectively), pond rent (7500 yuan $\left.\mathrm{ha}^{-1} \mathrm{yr}^{-1}\right)$, labor for daily management $(6 \mathrm{mo}$, including fish stocking and harvesting, lotus planting, fertilizing, routine work, etc.) and labor for harvesting lotus (1.5 yuan $\mathrm{kg}^{-1}$ harvested lotus).

\section{Statistical analysis}

All data were expressed as mean \pm SD. One-way ANOVA was used to determine the differences among treatments followed by a Tukey test to evalu- ate differences among treatment means for post hoc comparisons. Differences were considered significant at $\mathrm{p}<0.05$. All analyses were performed using the SPSS 16.0 statistical package.

\section{RESULTS}

\section{Lotus harvesting}

The per unit yield of the lotus, ranging from 20905 $\mathrm{kg} \mathrm{ha}{ }^{-1}$ in treatment I to $24581 \mathrm{~kg} \mathrm{ha}^{-1}$ in treatment IV (with $20905 \pm 5338,21110 \pm 3527,22950 \pm 3520$, $24581 \pm 4957,22662 \pm 3549 \mathrm{~kg} \mathrm{ha}^{-1}$ in treatments I, II, III, IV and V, respectively; see Table 1 for treatment specifics), were not significantly different among the 5 stocking density treatments $\left(F_{4}=0.375, \mathrm{p}=\right.$ $0.822)$, although a slight increase trend in yield was observed with increasing stocking density except in the highest density treatment.

\section{Survival and growth of the fish}

Performance parameters (mean \pm SD) of the 3 carp species reared for a 6 mo period in lotus fields at 5 stocking densities are shown in Table 2. The survival rates of the crucian carp, common carp and grass carp in the different treatments ranged from 46.8$64.2 \%, 48.4-58.2 \%$ and $45.3-60.4 \%$, respectively. No significant differences were found in the 4 fish stocking densities for the 3 species (crucian carp: $F_{3}=$ $0.641, \mathrm{p}=0.610$; common carp: $F_{3}=0.851, \mathrm{p}=0.504$; grass carp: $F_{3}=1.483, \mathrm{p}=0.291$ ). At the end of the study, however, there were significant differences among the stocking density treatments in the WG for each fish species (crucian carp: $F_{3}=6.340, \mathrm{p}=0.017$; common carp: $F_{3}=10.857, \mathrm{p}=0.003$; grass carp: $F_{3}=$ 13.915, p = 0.001), with the lowest values observed in the highest stocking density treatment. The AGR and SGR values showed a similar trend, with each of their values significantly decreasing with increasing stocking density in each of the 3 species (AGR: crucian carp: $F_{3}=5.349, \mathrm{p}=0.036$; common carp: $F_{3}=$ 12.566, $\mathrm{p}=0.002$; grass carp: $F_{3}=4.911, \mathrm{p}=0.041$; SGR: crucian carp: $F_{3}=5.704, \mathrm{p}=0.032$; common carp: $F_{3}=10.396, \mathrm{p}=0.004 ;$ grass carp: $F_{3}=4.890$, $\mathrm{p}=0.042$ ). The total yield for each species showed significant differences between treatments (crucian carp: $F_{3}=10.933, \mathrm{p}=0.002$; common carp: $F_{3}=$ 12.596, $\mathrm{p}=0.002$; grass carp: $F_{3}=6.785, \mathrm{p}=0.014$ ) with the highest and lowest values found in treatments V and II, respectively. 
Table 2. Performance parameters of 3 carp species reared for 6 mo at 5 stocking density treatments (I to V: 0, 1500, 3000, 4500 and 6000 ind. ha ${ }^{-1}$ ) in lotus fields. WG: relative weight gain; AGR: absolute growth rate; SGR: specific growth rate. Data are presented as means $\pm \mathrm{SD}$; different superscripts in each row indicate significant differences $(\mathrm{p}<0.05)$ between stocking densities

\begin{tabular}{|llccccc|}
\hline \multirow{2}{*}{ Parameter } & Fish species & \multirow{2}{*}{ Treatment I } & Treatment II & Treatment III & Treatment IV & Treatment V \\
\hline Survival (\%) & Crucian carp & - & $64.2 \pm 5.9^{\mathrm{a}}$ & $60.2 \pm 13.5^{\mathrm{a}}$ & $46.8 \pm 9.5^{\mathrm{a}}$ & $57.3 \pm 8.3^{\mathrm{a}}$ \\
& Common carp & - & $56.4 \pm 3.3^{\mathrm{a}}$ & $58.2 \pm 5.9^{\mathrm{a}}$ & $48.4 \pm 4.9^{\mathrm{a}}$ & $54.6 \pm 6.8^{\mathrm{a}}$ \\
& Grass carp & - & $46.3 \pm 8.5^{\mathrm{a}}$ & $60.4 \pm 7.8^{\mathrm{a}}$ & $45.3 \pm 1.6^{\mathrm{a}}$ & $45.3 \pm 7.7^{\mathrm{a}}$ \\
WG $(\mathrm{g})$ & Crucian carp & - & $413.2 \pm 29.6^{\mathrm{a}}$ & $389.8 \pm 69.1^{\mathrm{a}}$ & $306.5 \pm 28.9^{\mathrm{a}, \mathrm{b}}$ & $256.5 \pm 32.1^{\mathrm{b}}$ \\
& Common carp & - & $489.5 \pm 6.7^{\mathrm{b}}$ & $582.8 \pm 28.9^{\mathrm{a}}$ & $399.5 \pm 33.3^{\mathrm{c}}$ & $364.5 \pm 32.4^{\mathrm{c}}$ \\
& Grass carp & - & $1053.0 \pm 240.4^{\mathrm{a}}$ & $603.0 \pm 60.1^{\mathrm{a}, \mathrm{b}}$ & $619.6 \pm 185.6^{\mathrm{a}, \mathrm{b}}$ & $425.0 \pm 43.5^{\mathrm{b}}$ \\
AGR $\left(\mathrm{g} \mathrm{d}^{-1}\right)$ & Crucian carp & - & $1.97 \pm 0.24^{\mathrm{a}}$ & $1.86 \pm 0.49^{\mathrm{a}}$ & $1.46 \pm 0.24^{\mathrm{ab}}$ & $1.22 \pm 0.27^{\mathrm{b}}$ \\
& Common carp & - & $2.33 \pm 0.05^{\mathrm{b}}$ & $2.78 \pm 0.24^{\mathrm{a}}$ & $1.90 \pm 0.28^{\mathrm{c}}$ & $1.74 \pm 0.27^{\mathrm{c}}$ \\
& Grass carp & - & $5.01 \pm 1.98^{\mathrm{a}}$ & $2.87 \pm 0.49^{\mathrm{a}, \mathrm{b}}$ & $2.95 \pm 1.53^{\mathrm{a}, \mathrm{b}}$ & $2.02 \pm 0.36^{\mathrm{b}}$ \\
SGR $\left(\% \mathrm{~d}^{-1}\right)$ & Crucian carp & - & $0.80 \pm 0.05^{\mathrm{a}}$ & $0.76 \pm 0.10^{\mathrm{a}}$ & $0.69 \pm 0.06^{\mathrm{a}, \mathrm{b}}$ & $0.62 \pm 0.07^{\mathrm{b}}$ \\
& Common carp & - & $0.78 \pm 0.01^{\mathrm{a}, \mathrm{b}}$ & $0.85 \pm 0.03^{\mathrm{a}}$ & $0.70 \pm 0.05^{\mathrm{b}, \mathrm{c}}$ & $0.67 \pm 0.06^{\mathrm{c}}$ \\
& Grass carp & - & $0.59 \pm 0.15^{\mathrm{a}}$ & $0.43 \pm 0.05^{\mathrm{a}, \mathrm{b}}$ & $0.42 \pm 0.14^{\mathrm{a}, \mathrm{b}}$ & $0.34 \pm 0.04^{\mathrm{b}}$ \\
Total yield $\left(\mathrm{kg} \mathrm{ha}^{-1}\right)$ & Crucian carp & - & $195.5 \pm 29.2^{\mathrm{a}}$ & $367.8 \pm 46.4^{\mathrm{b}}$ & $327.6 \pm 67.3^{\mathrm{b}}$ & $493.7 \pm 88.3^{\mathrm{c}}$ \\
& Common carp & - & $205.3 \pm 13.0^{\mathrm{a}}$ & $492.9 \pm 39.6^{\mathrm{b}}$ & $446.2 \pm 42.1^{\mathrm{b}}$ & $639.8 \pm 83.5^{\mathrm{c}}$ \\
& Grass carp & - & $198.7 \pm 76.5^{\mathrm{a}}$ & $374.1 \pm 80.9^{\mathrm{b}}$ & $421.0 \pm 90.3^{\mathrm{bc}}$ & $462.0 \pm 88.9^{\mathrm{c}}$ \\
\hline
\end{tabular}

\section{Economic benefit analysis}

The comparative costs and return analysis for the 3 carp species cultured in lotus fields for 6 mo for each of the 5 different treatments are shown in Table 3. There were significant differences in total revenue, total costs and net income among density treatments (total revenue: $F_{4}=4.131, \mathrm{p}=0.032$; total costs: $F_{4}=$ $5.405, \mathrm{p}=0.014$; net income: $F_{4}=3.488, \mathrm{p}=0.041$ ).
The total revenue was highest in treatment IV and lowest in treatment I, with the total costs significantly increasing with increased density. Total net income was highest in treatment IV and lowest in treatment $I$, while no significant differences was observed between treatments III and IV $(p=0.872)$. The revenue from lotus was the major contributor to the total net revenue realized in the 5 treatments. Compared with the control treatment, the revenue generated

Table 3. Economic benefit analysis of 3 carp species reared for 6 mo at 5 stocking density treatments in lotus fields. ROI: ratio of output and input. Values are means \pm SE of 3 replicates; different superscripts in the same row indicate significant differences $(p<0.05)$

\begin{tabular}{|c|c|c|c|c|c|c|}
\hline Item & Amount and rate & Treatment I & Treatment II & Treatment III & Treatment IV & Treatment V \\
\hline Total revenue & $10^{4}$ yuan ha ${ }^{-1}$ & $12.54 \pm 1.85^{\mathrm{a}}$ & $13.43 \pm 1.16^{\mathrm{a}}$ & $15.33 \pm 0.92^{b}$ & $16.27 \pm 1.67^{b}$ & $15.60 \pm 1.61^{b}$ \\
\hline Lotus & 6 yuan $\mathrm{kg}^{-1}$ & $12.54 \pm 1.85^{\mathrm{a}}$ & $12.67 \pm 1.22^{\mathrm{a}}$ & $13.77 \pm 1.22^{\mathrm{a}}$ & $14.75 \pm 1.71^{\mathrm{a}}$ & $13.60 \pm 1.23^{\mathrm{a}}$ \\
\hline Crucian carp & 12 yuan $\mathrm{kg}^{-1}$ & - & $0.23 \pm 0.02^{\mathrm{a}}$ & $0.44 \pm 0.15^{\mathrm{b}}$ & $0.39 \pm 0.16^{b}$ & $0.59 \pm 0.13^{\mathrm{c}}$ \\
\hline Common carp & 12 yuan $\mathrm{kg}^{-1}$ & - & $0.25 \pm 0.01^{\mathrm{a}}$ & $0.59 \pm 0.08^{b}$ & $0.54 \pm 0.03^{b}$ & $0.77 \pm 0.13^{c}$ \\
\hline Grass carp & 14 yuan $\mathrm{kg}^{-1}$ & - & $0.28 \pm 0.06^{\mathrm{a}}$ & $0.52 \pm 0.09^{\mathrm{b}}$ & $0.59 \pm 0.11^{\mathrm{b}, \mathrm{c}}$ & $0.65 \pm 0.14^{\mathrm{c}}$ \\
\hline Total cost & $10^{4}$ yuan ha ${ }^{-1}$ & $8.96 \pm 0.46^{\mathrm{a}}$ & $9.56 \pm 0.31^{\mathrm{a}, \mathrm{b}}$ & $10.22 \pm 0.30^{a, b}$ & $10.86 \pm 0.43^{b}$ & $10.96 \pm 0.31^{b}$ \\
\hline Lotus seed & 8 yuan $\mathrm{kg}^{-1}$ & 36000 & 36000 & 36000 & 36000 & 36000 \\
\hline Crucian carp fingerling & 1.2 yuan ind. $^{-1}$ & - & 720 & 1440 & 2160 & 2880 \\
\hline Common carp fingerling & 1.3 yuan ind $^{-1}$ & - & 780 & 1560 & 2340 & 3120 \\
\hline Grass carp fingerling & 8 yuan ind..$^{-1}$ & - & 2400 & 4800 & 7200 & 9600 \\
\hline Field rental cost & 9000 yuan ha ${ }^{-1}$ & 7500 & 7500 & 7500 & 7500 & 7500 \\
\hline Fertilizer & 9000 yuan ha ${ }^{-1}$ & 7500 & 7500 & 7500 & 7500 & 7500 \\
\hline $\begin{array}{l}\text { Labor for daily } \\
\text { management ( } 6 \mathrm{mo})\end{array}$ & 1500 yuan ha ${ }^{-1} \mathrm{mo}^{-1}$ & 7200 & 9000 & 9000 & 9000 & 9000 \\
\hline Labor for harvesting lotus & 1.5 yuan $\mathrm{kg}^{-1}$ & $3.14 \pm 0.46^{\mathrm{a}}$ & $3.17 \pm 0.31^{\mathrm{a}}$ & $3.44 \pm 0.30^{\mathrm{a}}$ & $3.69 \pm 0.43^{\mathrm{a}}$ & $3.40 \pm 0.31^{\mathrm{a}}$ \\
\hline Fish net income & $10^{4}$ yuan ha ${ }^{-1}$ & - & $0.37 \pm 0.07^{\mathrm{a}}$ & $0.78 \pm 0.15^{b}$ & $0.34 \pm 0.06^{\mathrm{a}}$ & $0.45 \pm 0.11^{\mathrm{a}}$ \\
\hline Total net income & $10^{4}$ yuan ha ${ }^{-1}$ & $3.59 \pm 1.38^{a}$ & $3.87 \pm 01.85^{a}$ & $5.10 \pm 0.62^{b, c}$ & $5.41 \pm 1.24^{\mathrm{c}}$ & $4.64 \pm 1.30^{\mathrm{a}, \mathrm{b}}$ \\
\hline ROI & - & $1.39 \pm 0.13^{\mathrm{a}}$ & $1.40 \pm 0.07^{\mathrm{a}}$ & $1.50 \pm 0.05^{\mathrm{a}}$ & $1.49 \pm 0.10^{\mathrm{a}}$ & $1.44 \pm 0.04^{\mathrm{a}}$ \\
\hline
\end{tabular}


from the 3 carp species in the fish stocking treatments accounted for $5.65-12.86 \%$ of the total revenue. The major expenses (of the total costs) were for the lotus seed and the labor for harvesting the lotus, representing $>60 \%$ of the total costs for all treatments. The ratios of output and input (ROI) were not significantly different among treatments, but the ROI of the fish stocking treatments were higher compared with that of the control treatment.

\section{Pest abundance}

Spodoptera litura (Fabricius) larvae (Lepidoptera: Noctuidae), Rhopalosiphum nymphaeae (L.) (Hemiptera: Aphididae) and Chironomidae spp. (Diptera) were the 3 most predominant lotus pests in the fields during our investigation (Fig. 2). The abundance of $S$. litura larvae showed similar temporal trends in the 5 density treatments by initially increasing and then decreasing between June and September. No significant difference was observed among treatments in any of the months (all p >0.05; Fig. 2, Table 4), but their abundance was lower in the fish stocking treatments than in the control treatment from July to September. The abundance of $R$. nymphaeae showed similar variation trends in the 5 density treatments by increasing initially, then decreasing, and increasing again between May and September. At the beginning, there was no significant difference in abundance among treatments ( $p>0.05$; Fig. 2, Table 4), but significantly higher numbers were observed in the control compared to the 4 fish stocking treatments from June to September (all p < 0.05; Fig. 2, Table 4). The abundance of chironomid pests was highest in June, lowest in July and then increased again in subsequent months. Their abundance in the 4 fish stocking treatments was significantly lower than in the control treatment from June to September (all $\mathrm{p}<0.05$; Fig. 2, Table 4).

\section{DISCUSSION}

In the present study, the per unit yields of lotus were not significantly different among the 5 stocking density treatments, although it tended to increase slightly with increasing stocking density, except in the highest density treatment. This indicates that moderate fish stocking in lotus fields not only has no negative effects on the production of lotus, but also actually benefits the growth of the crop. Similar results have been observed in rice-fish and rice-crab
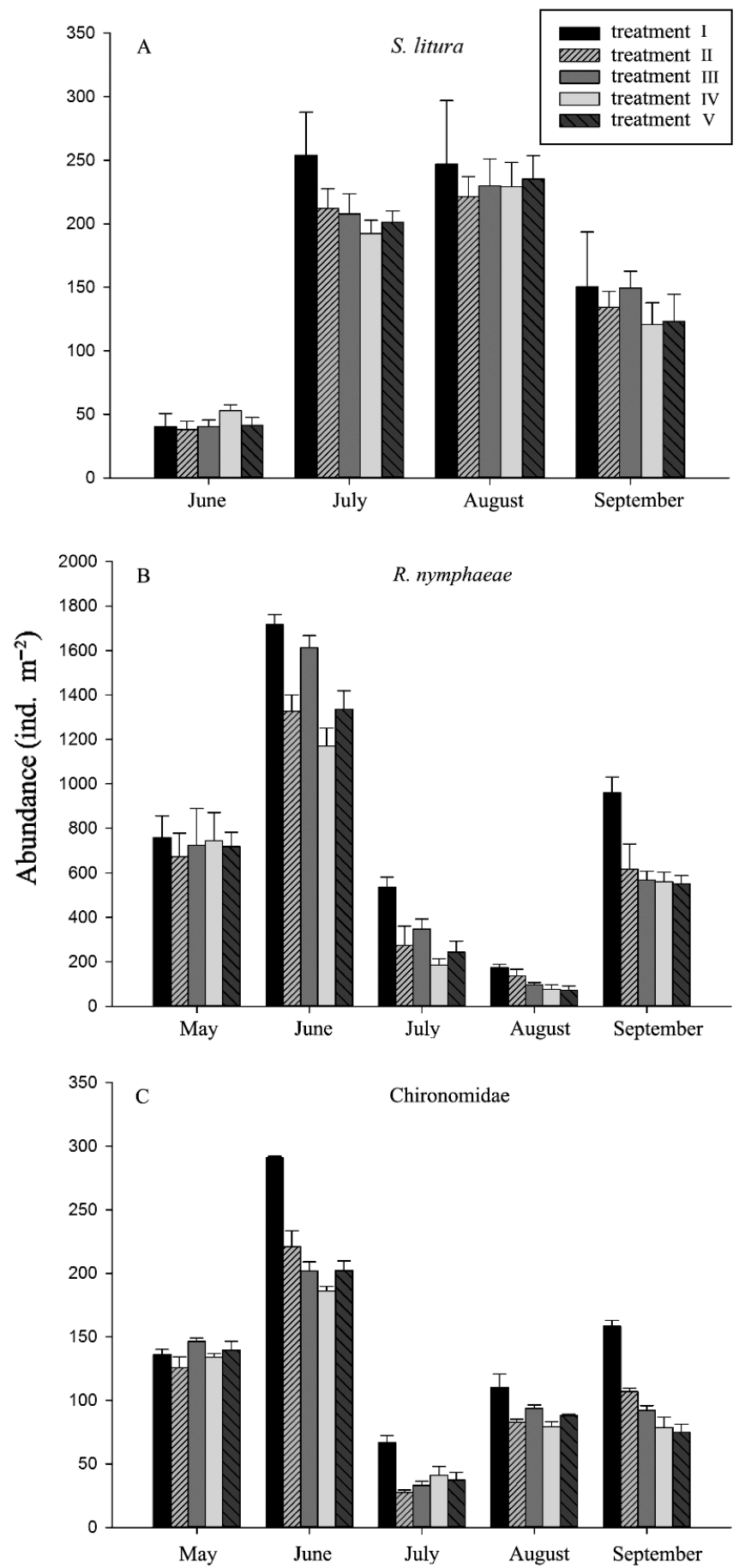

Fig. 2. Abundance of 3 main pests in 5 stocking density treatments in different months in the lotus fields: (A) Spodoptera litura, (B) Rhopalosiphum nymphaeae, (C) Chironomidae

culture systems, where fish or crabs reared in paddy fields were shown to have no negative effects on rice production (Cagauan et al. 2000, Li et al. 2007). In a review of 18 rice-fish studies, it was demonstrated that the tendency of integrating fish with rice was to 
Table 4. Summary results comparing the abundance of the 3 most predominant lotus pests in different months in 5 stocking density treatments in lotus fields. Significant p-values $(p<0.05)$ are shown in bold

\begin{tabular}{|lrrc|}
\hline Source of variance & $\mathrm{df}$ & $F$ & $\mathrm{p}$ \\
\hline Spodoptera litura larvae & & & \\
June & 4 & 1.222 & 0.361 \\
July & 4 & 2.463 & 0.114 \\
August & 4 & 0.508 & 0.731 \\
September & 4 & 0.943 & 0.478 \\
Rhopalosiphum nymphaeae & & & \\
May & 4 & 0.234 & 0.913 \\
June & 4 & 30.856 & $\mathbf{0 . 0 0 0}$ \\
July & 4 & 18.100 & $\mathbf{0 . 0 0 0}$ \\
August & 4 & 13.344 & $\mathbf{0 . 0 0 1}$ \\
September & 4 & 20.344 & $\mathbf{0 . 0 0 0}$ \\
Chironomid pests & & & \\
May & 4 & 0.828 & 0.537 \\
June & 4 & 30.146 & $\mathbf{0 . 0 0 0}$ \\
July & 4 & 8.596 & $\mathbf{0 . 0 0 3}$ \\
August & 4 & 5.142 & $\mathbf{0 . 0 1 6}$ \\
September & 4 & 18.976 & $\mathbf{0 . 0 0 0}$ \\
\hline
\end{tabular}

improve rice yields (4.6-28.6\%) (Lightfoot et al. 1992). In the present study, lotus production in fish stocking treatments increased $1-17.6 \%$ over the control treatment. This beneficial effect of fish stocking on lotus production is possibly related to increased nutrients (primarily nitrogen) availability in the soil as a result of fish activity in the lotus fields, as pointed out in similar reports involving rice-fish ecosystems (Panda et al. 1987, Lightfoot et al. 1992). Additionally, the reduction in the pest population in the lotus-fish culture system may be another factor responsible for the improved growth and production of lotus. The interaction between lotus and fish in lotus-fish system is complex, involving many factors, and needs to be studied further.

Stocking density is one of the most important factors that directly influence the survival, growth, behavior, feeding and production of many species. Thus, the determination of the most advantageous stocking density for cultured animals is essential in order to optimize production, profitability and sustainability (Imani et al. 2014). Although a positive effect of stocking density on growth is found in some species, an inverse relationship between these factors is more frequently reported (Weatherley 1976, Namukose et al. 1996, Hwang et al. 2014). Increasing stocking density results in stress (Leatherland \& Cho 1985), which, in turn, leads to increased energy requirements and reduction in growth and food utilization (Hengsawat et al. 1997). In this study, the
WG, AGR and SGR showed similar trends in that their values significantly decreased with increasing stocking density in each of the 3 carp species. This indicates that fish growth is density-dependent during the grow-out phase of production in lotus fields. Density-dependent growth has been reported for fish (Sahoo et al. 2004, Schram et al. 2006), for penaeid shrimp species in tanks (Coman et al. 2004, EsparzaLeal et al. 2015), and for crabs in rice fields (Li et al. 2007). The main factor in the decrease of growth was probably food resource competition (Li et al. 2007, Esparza-Leal et al. 2015). The limited food resources available in the lotus fields in the present study, where supplemental food resources were not supplied, would likely impede fish growth at higher stocking densities.

Survival rates were not affected by stocking density in this study. Similar results have been reported for many fish species in cages or ponds (Hwang et al. 2014, Imani et al. 2014). However, many studies have found significantly negative effects of density on survival (Chakraborty \& Mirza 2007, Li et al. 2007, Neal et al. 2010). The inconsistency of effects of stocking density on survival is probably attributable to experimental space, living habits and the capacity to adapt to the environment in different cultured species. Compared to tanks or cages, a lotus field is capable of providing an assortment of different food resources, such as zoobenthos, lotus pests, weeds and plankton, although their biomass was limited in this study. Crucian carp, common carp and grass carp, with different spatial and nutritive niches, high adaptability to varying environments and a lack of aggressive behavior toward each other, could, therefore, alternatively use limited food resources to maintain survival rates similar to the densities found in our study (1500-6000 ind. ha ${ }^{-1}$ ).

In our study, the higher net income in 4 of the 5 lotus-fish culture treatments indicates that fish stocking is effective in producing beneficial results on production performance in lotus fields. Net income was higher in the 3000 and 4500 ind. ha ${ }^{-1}$ treatments, mainly due to the higher lotus yield and lower cost of fish fingerlings compared to other treatments. It can be concluded that reasonable stocking density of fish was rather important, not only in terms of the improvement of growth and economic points of view, but also considering the ecological benefits resulting from fewer lotus pests. The fish species stocked is also an important consideration in the total net income from lotus fields. In this study, the net income of 3 different carp species accounted for 6.43$15.21 \%$ of the total net income, with the apparent dif- 
ference due to the fish species used. The net income from using grass carp was lower in each fish stocking treatment compared with that from using crucian and common carp, with the cost even surpassing the revenue for grass carp in the 4500 and 6000 ind. ha ${ }^{-1}$ treatments. This does suggest that crucian and common carp are preferable to grass carp for stocking in lotus fields, and that the stocking density of grass carp needs to be $<600$ ind. $\mathrm{ha}^{-1}$.

In the present study, we found that the abundance of the 3 major pests (Spodoptera litura larvae, Rhopalosiphum nymphaeae and Chironomidae spp.) in lotus-fish culture systems were lower than those in lotus monoculture systems. This is the first validation study of pest control in lotus fields as a result of fish stocking. The decreased abundance of pests on the lotus plants is likely attributable mostly to fish feeding. It is also quite possible that pests on the stems and leaves of the lotus are physically knocked into the water and drowned as a result of increased agitation of the lotus plants due to the activity of the fish. The abundance of $R$. nymphaeae and chironomid individuals was significantly lower in the fish stocking treatments compared to the control treatment. There was no significant difference in the abundance of $S$. litura larvae between the non-fish and fish stocking treatments, although fewer of the pests were observed in lotus-fish culture systems from July to September. The difference was likely related to their microhabitat. $R$. nymphaeae and chironomid species feed mainly on the floating leaves, or the tender leaves and shoots of lotus plants close to the surface of the water (Wang \& Ye 1986, Chen et al. 2013). In contrast, $S$. litura larvae are mainly found on emergent lotus leaves, or lotus flowers and ovaries above the waterline (Zhu et al. 2013).

\section{CONCLUSIONS}

Fish stocking is shown to have beneficial effects on pest control and plant performance in lotus fields, allowing for optimal utilization of the available space in lotus fields, and contributing substantially to improving the economic output and pest control in such an integrated system. Stocking densities of the 3 carp species tested had a significant effect on the WG, AGR and SGR values, but did not negatively affect fish survival rates or lotus production. The abundance of lotus pests declined with increasing stocking density. Considering the net profits as well as the growth performance of the 3 carp species, a stocking density of 3000-4200 total ind. ha ${ }^{-1}$ (crucian carp: $1200-1800$ ind. $\mathrm{ha}^{-1}$; common carp: $1200-1800$ ind. ha ${ }^{-1}$; grass carp: $<600$ ind. $\mathrm{ha}^{-1}$ ) is considered optimal in lotus-fish culture systems.

Acknowledgements. The authors thank Prof. Brendan Hicks and Dr. Casey Clark for their constructive comments and critically reading of the manuscript, and Dr. Cecil L. Smith (University of Georgia, USA) for editing and revising the English language. The present research was supported by a grant from the National Scientific and Technological Supporting Program of China (no. 2012BAD27B02).

\section{LITERATURE CITED}

Cagauan AG, Branckaert RD, van Hove C (2000) Integrating fish and azolla into rice-duck farming in Asia. Naga 23: $4-10$

Chakraborty BK, Mirza MJA (2007) Effect of stocking density on survival and growth of endangered bata, Labeo bata (Hamilton-Buchanan) in nursery ponds. Aquaculture 265:156-162

Chen YS, Li ZJ (2007) Analysis of environmental and economical effectiveness in planting lotus in typical fish ponds in areas along the middle reaches of the Yangtze River. Resour Environ Yangtze Basin 16:609-614

Chen Q, Ma L, Zhu J, Wei Y, Huang GH (2013) Biological characteristics and control of Rhopalosiphum nymphaeae (Linnaeus, 1761). J Changjiang Veg 18:116-118

* Coman GJ, Crocos PJ, Presto NP, Fielder D (2004) The effects of density on the growth and survival of different families of juvenile Penaeus japonicus Bate. Aquaculture 229:215-223

Edwards P (1987) Use of terrestrial vegetation and aquatic macrophytes in aquaculture. In: Moriarty DJW, Pullin RSV (eds) Detritus and microbial ecology in aquaculture. ICLARM Conference Proceedings, Vol. 14. International Center for Living Aquatic Resources Management, Manila, Philippines, p 311-335

Esparza-Leal HM, Cardozo AP, Wasielesky W (2015) Performance of Litopenaeus vannamei postlarvae reared in indoor nursery tanks at high stocking density in clearwater versus biofloc system. Aquacult Eng 68:28-34

Follett JM, Douglas JA (2003) Lotus root: production in Asia and potential for New Zealand. Combined Proc Int Plant Prop Soc 53:79-83

Gomes LC, Chagas EC, Martins-Junior H, Roubach R, Ono EA, Lourenço JNP (2006) Cage culture of tambaqui (Colossoma macropomum) in a central Amazon floodplain lake. Aquaculture 253:374-384

*Hengsawat K, Ward FJ, Jaruratjamorn P (1997) The effect of stocking density on yield, growth and mortality of African catfish (Clarias gariepinus Burchell 1822) cultured in cages. Aquaculture 152:67-76

Hossain A, Sarker MAZ, Saifuzzaman M, Silva JATD, Lozovskaya MV, Akhter MM (2013) Evaluation of growth, yield, relative performance and heat susceptibility of eight wheat (Triticum aestivum L.) genotypes grown under heat stress. Int J Plant Prod 7:615-636

Huang GH, Li JH (2013) Color handbook of insect pests of aquatic vegetables in China. Changjiang Publishers Group, Wuhan

Hwang HK, Son MH, Myeong JI, Kim CW, Min BH (2014) 
Effects of stocking density on the cage culture of Korean rockfish (Sebastes schlegeli). Aquaculture 434:303-306 Imani K, Enock M, Nasser K (2014) Effect of stocking density on the growth performance of sex reversed male Nile tilapia (Oreochromis niloticus) under pond conditions in Tanzania. World J Fish Mar Sci 6:156-161

Ke WD, Huang XF, Li JH, Yan SL, Liu YM, Li F (2015) Development and research of aquatic vegetables in China. J Changjiang Veg 14:33-37

Leatherland JF, Cho CY (1985) Effect of rearing density on thyroid and interrenal gland activity and plasma hepatic metabolite levels in rainbow trout, Salmo gairdneri Richardson. J Fish Biol 27:583-592

Li X, Dong S, Lei Y, Li Y (2007) The effect of stocking density of Chinese mitten crab Eriocheir sinensis on rice and crab seed yields in rice-crab culture systems. Aquaculture 273:487-493

Lightfoot CA, van Dam A, Costa-Pierce BA (1992) What's happening to the rice yields in rice-fish systems? In: Dela Cruz CR, Lightfoot C, Costa-Pierce BA, Carangal VR, Bimbao MP (eds) Rice-fish research and development in Asia. International Center for Living Aquatic Resource Management Conference Proceedings, Vol. 24. International Center for Living Aquatic Resource Management, Manila, p 177-183

Liu YM, Fu XF (2004) How to improve the effect for planting lotus. Shanghai Veg 4:13-14

Ma L, Zhu J, Chen Q, Li W, Huang GH (2016) Effect of fish stocking density on diversity of arthropod community in lotus field. J Hunan Agr Univ Nat Sci 42:64-69

Namukose M, Msuya FE, Ferse SCA, Slater MJ, Kunzmann A (2016) Growth performance of the sea cucumber Holothuria scabra and the seaweed Eucheuma denticulatum: integrated mariculture and effects on sediment organic characteristics. Aquacult Environ Interact 8:179-189

Neal RS, Coyle SD, Tidwell JH (2010) Evaluation of stocking density and light level on the growth and survival of the Pacific white shrimp, Litopenaeus vannamei, reared in zero-exchange systems. J World Aquacult Soc 41:533-544

Editorial responsibility: Alejandro Buschmann, Puerto Montt, Chile
Nguyen QV (2001) Lotus for export to Asia-an agronomic and physiological study. RIRDC Publication, Barton

*Panda MM, Ghosh BC, Sinhababu DP (1987) Uptake of nutrients by rice under rice-cum-fish culture in intermediate deep water situation (up to 50-cm water depth). Plant Soil 102:131-132

Sahoo SK, Giri SS, Sahu AK (2004) Effect of stocking density on growth and survival of Clarias batrachus (Linn.) larvae and fry during hatchery rearing. J Appl Ichthyol 20:302-305

Schram E, Heul JWVD, Kamstra A, Verdegem MCJ (2006) Stocking density-dependent growth of Dover sole (Solea solea). Aquaculture 252:339-347

Tan Y, Li S, Sun L (2003) The pollution of pesticides to the water environment. Pesticides 42:12-14

Tian DK, Tilt KM, Woods FM, Sibley JL, Dane F (2006) Summary of development, introduction and marketing strategy to share lotus in the Southeast United States. Proc 13th Annu Conf Int Plant Prop Soc, Wakayama 56: 151-154

Tian DK, Tilt KM, Sibley JL, Woods FM, Dane F (2009) Response of lotus (Nelumbo nucifera Gaertn.) to planting time and disbudding. HortScience 44:656-659

Wang S, Ye Y (1986) Occurrence characteristics of Stenichironomus nelumbus (Tokunaga \& Kuroda) on lotus and its related control technology. Entomol Knowledge 2:73-74

*Weatherley AH (1976) Factors affecting maximization of fish growth. J Fish Res Board Can 33:1046-1048

Wu W (2005) Production in lotus-fish co-culture field. Fujian Agr 2:28-29

Xiong J, Wu LJ, Du J, Huang GH (2010) Control methods and damage characteristics of the main insect pest of lotus. J Changjiang Veg 14:94-98

*Yi Y, Lin CK, Diana JS (2002) Recycling pond mud nutrients in integrated lotus-fish culture. Aquaculture 212:213-226

Zhu J, Niu C, Zhang Z, Zhao J, Li J, Gong Z (2013) Occurrence characteristics of Spodoptera litura (Fabricius) on lotus and its related green control technology. J Changjiang Veg 18:113-115

Submitted: February 10, 2017; Accepted: June 27, 2017

Proofs received from author(s): August 27, 2017 